\title{
HYMENOPTERA MARKING TECHNIQUE
}

\section{PEREIRA A. M. (1), CHAUD-NETTO J. (1)}

(1) Rio Claro Institute of Biosciences, São Paulo State University-UNESP, Rio Claro, São Paulo State, Brazil.

ABSTRACT: In true social hymenopterans, such as many species of bees, wasps and all species of ants, the main characteristics are the overlapping of generations, the care with the offspring and the division of labor among the members of the colony. The first biological feature means that in a same moment there are groups of individuals, with variable ages, that execute different activities in the colony. In order to study the division of labor among the members of the colony, or to estimate the life span of these insects, or even to analyze any kind of behavior in non-social insects, it is necessary to know the exact age of each individual. For this reason, the insects must be identified soon after emergence. The identification of insects with numbers is an important technological improvement in behavioral studies, mainly in honeybee colonies. The aim of this scientific note is to describe an easy and cheaper technique for marking hymenopterans.

KEY WORDS: Apis mellifera, Hymenoptera, marking technique, social insects.

CONFLICTS OF INTEREST: There is no conflict.

\section{CORRESPONDENCE TO:}

ANDRIGO MONROE PEREIRA, Avenida 24a, 1515, Bela Vista, 13506-900, Rio Claro, SP, Brasil. Email: andrigomp@hotmail.com. 


\section{INTRODUCTION}

The eusocial (true social) hymenopterans such as some species of bees, wasps and all species of ants present, as main characteristics, the overlapping of generations, the care with the offspring and the division of labor among the members of the colony (2). In some groups of hymenopterans, a morphological polyethism is observed. In this type of social regulation, the different tasks are executed by morphologically different individuals. In other groups, the age polyethism is present. In this case, the work division is related to the age of the individuals, although it is also influenced by genetic and environmental factors $(1,3)$.

In behavioral studies and, more precisely, in the division of labor among the members of a colony, it becomes necessary to know the age of each individual that executes a specific task. In studies with Apis mellifera, Sakagami (4) developed a marking system using a code of colors to identify members of the colony with variable ages. The utilization of this method is laborious because it takes in consideration the specific position of each colored mark on the thorax of each insect.

The identification of insects with numbered plastic discs pasted on the thorax is an important technological improvement in behavioral studies, mainly in honeybee colonies. The aim of this scientific note is to describe an easy and cheaper technique for the preparation and setting of such plastic discs. This method was initially elaborated for studies with $A$. mellifera, but it can also be used for marking other hymenopterans.

It can be used in insects that present approximately the same thorax size of $A$. mellifera (about $4.35 \mathrm{~mm}$ for workers and $6.43 \mathrm{~mm}$ for drones). A sequence of numbers from 00 to 99 (8-point type in Times New Roman) is printed in a white paper (these numbers can be printed in sheets of different colors to facilitate the marking of groups of insects with different ages). In each A4 sheet (21X29.7cm page size), some quadrants will be drawn, in order to make this numeration. These quadrants containing each set of numbers must be plasticized similarly to the plasticization of documents. In this process, the formation of air bubbles between the plastic and the paper must be prevented. Then, the numbers must be individually cut with a metallic hallowed cylinder (3-4mm of diameter) presenting a sharp extremity. Each plastic number, now with a disc form, must have a concave shape in order to afford a perfect adhesion to the thorax of the insect. For this purpose, a wooden piece 
containing perforations with diameter less than the size of the discs can be used. The discs must be placed with the number positioned toward the wood, being then lightly compressed against the perforation with tweezers. Each disc, now with the concave form, is carefully removed, and then can be adhered with plastic glue to the thorax of the insect (Figure 1). The glue generally used for polyvinyl chloride connecting tubes (PVC) is one of the most appropriate for this.

Hymenopterans with a well developed sting apparatus must be previously anesthetized with $\mathrm{CO}_{2}$ or even immobilized by cooling during some seconds, in order to prevent sting accidents at the moment of the marking. In studies with $A$. mellifera, newly emerged workers can be marked without previous anesthesia or immobilization because they are not capable of using the sting with entire efficiency.

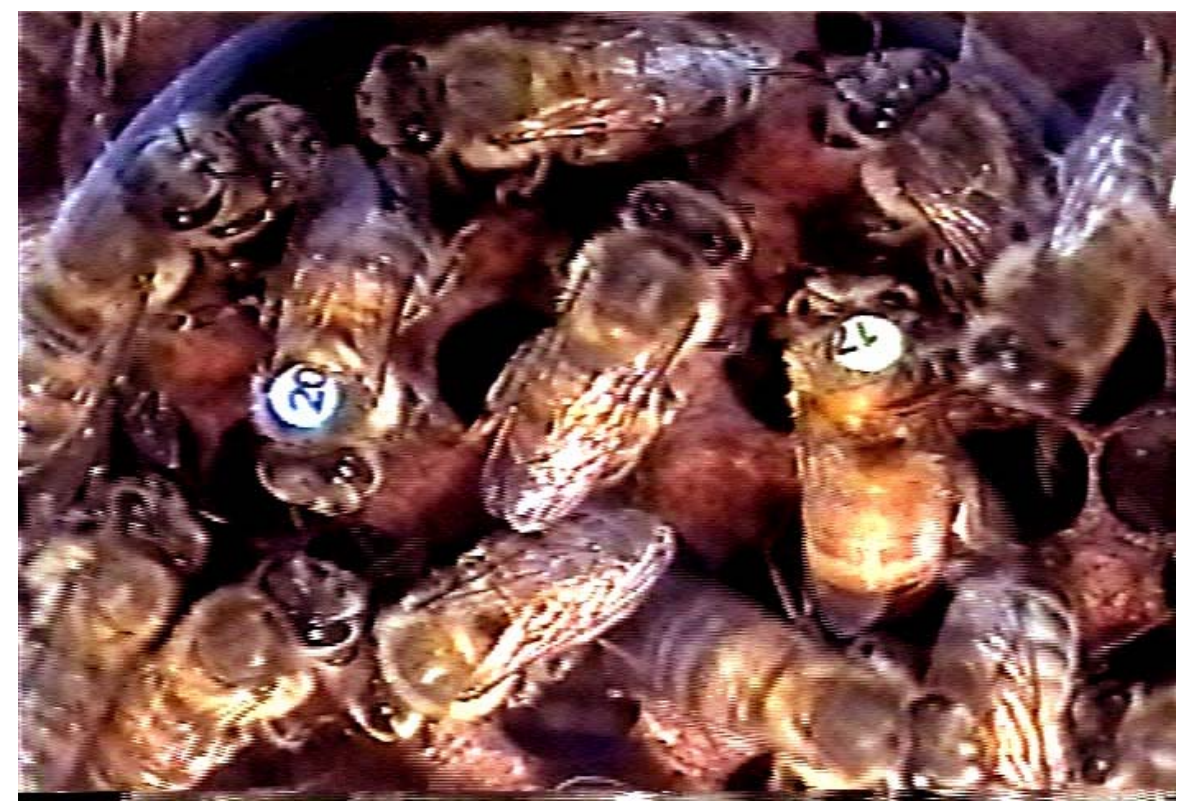

Figure 1. Two honeybee workers marked with numbered plastic discs: the bee on the left (20) is Africanized and the other (17) is Italian (Apis mellifera ligustica).

\section{ACKNOWLEDGEMENTS}

The authors are grateful to SESu/MEC and CNPq (National Council for Scientific and Technological Development) for the financial support of this research. 


\section{REFERENCES}

1 FREE JB. A organização social das abelhas. São Paulo: EPU-EDUSP, 1980, 79p. [Coleção Temas de Biologia, 13].

2 GULLAN PJ., CRANSTON PS. The insects: an outline of entomology. Oxford: Blackwell Publ., 2005. 528p.

3 MICHENER CD. The bees of the world. Baltimore: The Johns Hopkins University Press, 2000. 913 p.

4 SAKAGAMI SF. Techniques for the observation of behavior and social organization of stingless bees by using a special hive. Papéis Avulsos Dep. Zool. São Paulo, 1966, 19, 51-162. 